\title{
A Novel Multilayer Composite Membrane for Wound Healing in Mice Skin Defect Model
}

\author{
Yuyu Qiu ${ }^{1}$, Qingqing Wang ${ }^{2}$, Yajun Chen ${ }^{2}$, Shufang Xia ${ }^{1}$, Wei Huang ${ }^{1}$ and Qufu Wei ${ }^{2, *}$ \\ 1 Wuxi School of Medicine, Jiangnan University, Wuxi 214122, China; yuyuqiu1102@aliyun.com (Y.Q.); \\ xiashufang@jiangnan.edu.cn (S.X.); huangwei83721@163.com (W.H.) \\ 2 Key Laboratory of Eco-Textiles, Ministry of Education, Jiangnan University, Wuxi 214122, China; \\ qqwang@jiangnan.edu.cn (Q.W.); m18861824955@163.com (Y.C.) \\ * Correspondence: qfwei@jiangnan.edu.cn
}

Received: 3 February 2020; Accepted: 26 February 2020; Published: 4 March 2020

check for updates

\begin{abstract}
To develop a wound dressing material that conforms to the healing process, we prepared a multilayer composite (MC) membrane consisting of an antibacterial layer (ABL), a reinforcement layer (RFL), and a healing promotion layer (HPL). Biocompatible zein/ethyl cellulose (zein/EC) electrospun nanofibrous membranes with in situ loaded antibacterial photosensitizer protoporphyrin (PPIX) and healing promotion material vaccarin (Vac) were, respectively, chosen as the ABL on the surface and the HPL on the bottom, between which nonwoven incorporated bacterial cellulose (BC/PETN) as the HPL was intercalated to enhance the mechanical property. Photodynamic antibacterial activity against Staphylococcus aureus and Pseudomonas aeruginosa was confirmed by the enlarged inhibition zones; meanwhile, satisfactory biocompatibility of the HPL was verified by scanning electronic microscopy (SEM) of L929 cells cultured on its surface. The potential effects on wound healing in a mice skin defect model of the MC membranes were also evaluated. The animal experiments demonstrated that the wound healing rate in the MC group was significantly increased compared with that in the control group $(p<0.05)$. Histopathological observation revealed an alleviated inflammatory response, accompanied with vascular proliferation in the MC group. The MC membranes significantly promoted wound healing by creating an antibacterial environment and promoting angiogenesis. Taken together, this MC membrane may act as a promising wound dressing for skin wound healing.
\end{abstract}

Keywords: multilayer composite membrane; wound dressing; wound healing; antibacterial activity; biocompatibility

\section{Introduction}

An open wound is a type of injury that happens when the skin is punctured, torn, or cut. It specifically refers to the epidermis of the skin damaged by a sharp injury in pathology [1]. The main factors that promote wound healing include mechanical protection of the localized wound, prevention of infection, absorption of wound exudates, and maintenance of the microenvironment [2]. Modern wound dressings are technical products that create an ideal healing environment for wounds [3]. Given these requirements, the ideal wound dressing should be designed with certain specialties, including excellent biocompatibility, good mechanical properties as barriers, the ability to create a native extracellular matrix to stimulate cell migration, ability to remove excessive exudates, and sustained drug release properties to prevent bacterial infections and promote tissue structure proliferation and recombination $[4,5]$. No particular dressing has all of these characteristics, which is why the dressing is selected only after strict assessment. Therefore, composite films composed of biocompatible polymer and multifunctional drugs as wound dressings have attracted great attention in the field of wound healing [6]. 
Recently, electrospinning membranes and scaffolds have aroused great interest because of their biomedical applications in wound dressing, such as drug delivery, cell migration scaffolds, and transportation of gas and nutrients $[7,8]$. Compared with the traditional wound dressing, electrospinning nanofibrous membranes have several advantages, including simulation of a natural extracellular matrix due to three-dimensional (3D) reticulate structure $[9,10]$, small pore size preventing bacteria invasion [11], high porosity to accommodate active ingredients and drug molecular particles [12], and high surface area to release loaded drugs effectively [13]. Thus, electrospun composite membranes have been widely used in the research areas of wound dressings. Since most electrospinning membranes are usually used to load single drug molecules, the composite membranes cannot achieve multiple drug effects simultaneously, which thus makes it difficult to meet clinical treatment needs [14]. Therefore, it is desirable in wound healing research that multiple drugs be loaded via the electrospinning procedure to achieve multi-effects, such as creating an antibacterial environment and promoting cell proliferation.

Winter proposed the concept of a moist healing environment, which creates and sustains the ideal conditions to activate autolytic debridement of the wound, protecting newly formed cells, promoting angiogenesis and epithelial regeneration, reducing pain, and protecting the wound from bacteria and contamination $[15,16]$. Foam, gel, hydrogel, and aerosol are common types of occlusive wound dressings, which maintain the proper humidity in the wound bed. Bacterial cellulose (BC), synthesized by Acetobacter xylinum, consists of nanofibers with a three-dimensional structure, bound together by hydrogen of inter-fibers and intra-fibers to form a dried-state or hydrogel [17]. With the unique properties of high hydrophilicity, tensile strength, crystallinity, and good biocompatibility, it is a promising material used in wound healing applications. Photodynamic antibacterial chemotherapy (PACT) is a method of producing reactive oxygen species to induce antibacterial effects with visible lights combined with photosensitizer molecules. Porphyrin compounds are commonly used photosensitizers because of their highly active oxygen production. Studies showed $[18,19]$ that the combination of protoporphyrin IX (PPIX) and BC membrane has a significant antibacterial effect on Staphylococcus aureus and Escherichia coli.

In this work, PPIX and Vaccarin (Vac) particles were, respectively, impregnated into zein/EC fibers by electrospinning and used as an antibacterial layer (ABL) on the top and healing promotion layer (HPL) on the bottom. PETN was immersed into BC culture solution to develop a reinforcement layer (RFL). The above layers were further compounded to obtain multilayer composite (MC) membranes (Figure 1). The morphology, component, and mechanical properties of the prepared membranes were evaluated by scanning electronic microscopy (SEM), Fourier transform infrared spectroscopy (FTIR), and an electronic universal testing machine, respectively. In addition, the hygroscopicity, antibacterial activity, biocompatibility in vitro, and wound healing in vivo of the as-prepared membranes were also assessed. This study paves an innovated way for creating multi-effective composite membranes, which would have a positive effect in the design of next-generation wound dressings. 


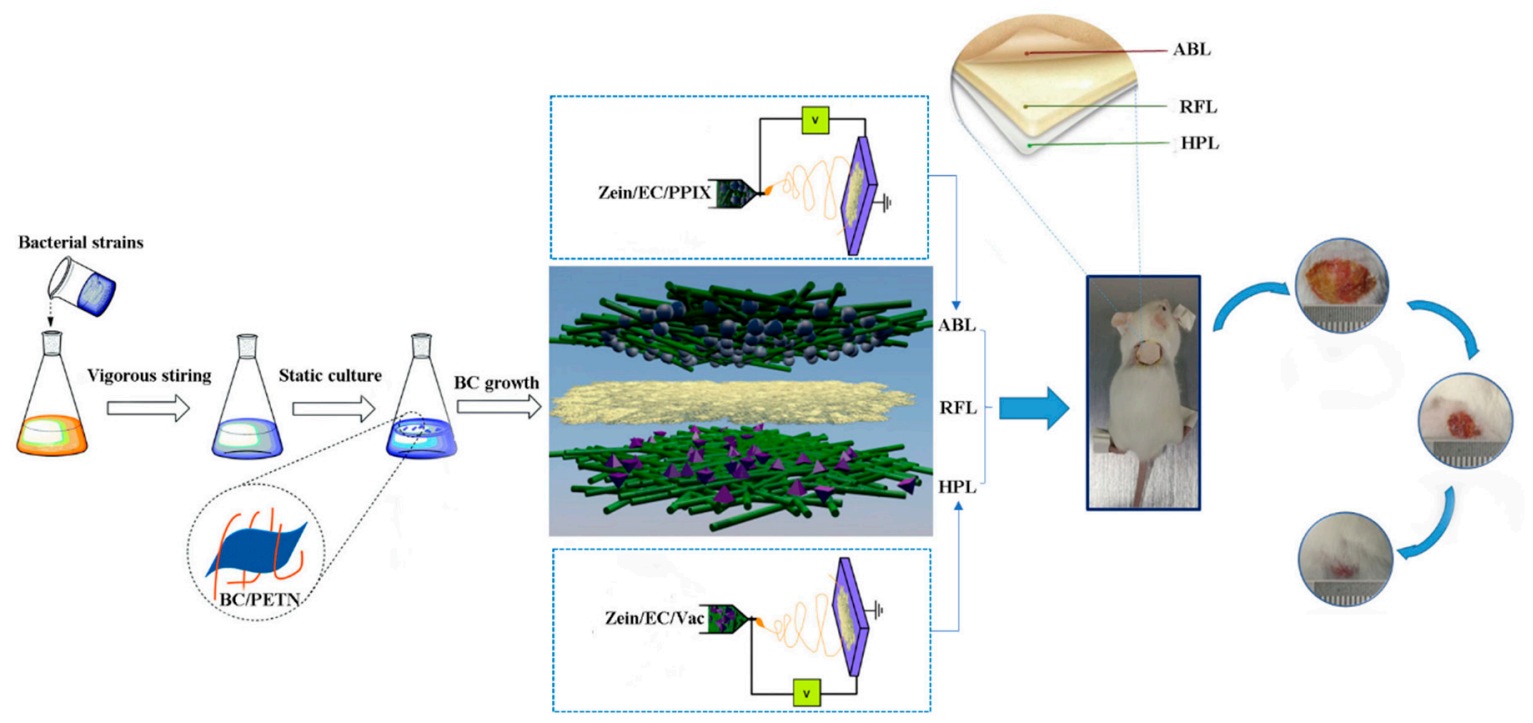

Figure 1. Schematic illustration of the preparation of multilayer composite (MC) membrane by electrospinning. ABL, antibacterial layer; RFL, reinforcement layer; HPL, healing promotion layer; BC, bacterial cellulose.

\section{Materials and Methods}

\subsection{Materials}

Vaccarin was purchased from Shanghai Shifeng Technology Co., Ltd. (Shanghai, China). Protoporphyrin IX (PPIX, MW = 562.66) was bought from Shanghai Vita Chemical Reagent Co., Ltd (Shanghai, China). Zein (MW = 35,000) was purchased from Sigma-Aldrich (St. Louis, MO, USA) Company. Ethyl cellulose (EC; 6-9 mPa s) was obtained from Aladdin Chemistry Co., Ltd. (Shanghai, China). Gluconacetobacter xylinus was cultured by our own lab. Polyester spun-laced nonwovens (40 $\mathrm{g} / \mathrm{m}^{2}$ ) were provided by Jiangyin Haiyue Non-woven Fabric Co., Ltd (Wuxi, China). The mouse skin fibroblast cells (L929 cells) were obtained from Shanghai Institutes for Biological Sciences. ICR male mice were gained from Shanghai Slac Laboratory Animal Co., Ltd. (Shanghai, China). All of the chemicals were of analytical grade. All animal experiments were performed in accordance with the Guidelines for the Care and Use of Laboratory Animals (Ministry of Science and Technology of China, 2006) and approved by the animal ethics committees of Jiangnan University (JN. No20180430c0480615).

\subsection{Preparation}

\subsubsection{Preparation of the ABL and the HPL}

The precursor solution was prepared by dissolving $2 \mathrm{~g}$ zein and $2 \mathrm{~g}$ EC in $10 \mathrm{~mL}$ acetic acid, and the entire solute concentration was maintained at $40 \%(w / v)$. The solution was stirred intensely at room temperature for $1 \mathrm{~h}$, then, $0.5 \%$ PPIX $(w / w)$ and $2 \%$ Vac $(w / w)$ were separately added to obtain the electrospinning solution, which were subsequently stirred for $12 \mathrm{~h}$. The obtained zein/EC/Vac and zein/EC/PPIX electrospinning solutions were, respectively, placed in syringes with a blunt-end metal capillary nozzle with a 1-mm core diameter. The parameters of the electrospinning apparatus were set to a voltage power $(18 \mathrm{kV})$, a constant flow rate at $0.5 \mathrm{~mL} / \mathrm{h}$, and a distance of $15 \mathrm{~cm}$ between the nozzle and collector. The nanofibers were deposited on the aluminum foil, which covered a circular rotating drum at room temperature.

\subsubsection{Preparation of the RFL}

G. xylinum was inoculated to the fermentation medium (D-mannitol $25 \mathrm{~g} / \mathrm{L}$, yeast extract $5 \mathrm{~g} / \mathrm{L}$, tryptone $3 \mathrm{~g} / \mathrm{L}$ ) in flakes and shaken gently so that the bacteria were evenly distributed in the culture 
medium. The bacterial cellulose membrane was formed after static incubation for a week at $30{ }^{\circ} \mathrm{C}$. The inoculated fermentation medium was also added into the petri dishes containing PETN, and then sealed with plastic wrap to culture the BC/PETN membrane. The obtained BC and BC/PETN membrane were purified in $4 \mathrm{wt} \% \mathrm{NaOH}$ solution to remove any bacteria and culture liquid, followed by rinsing with distilled water and freeze-drying.

\subsubsection{Preparation of the MC Membrane}

The MC membrane was prepared by using the zein/EC/PPIX nanofibrous membrane as the ABL, the BC/PETN membrane layer as the RFL, and the zein/EC/Vac nanofibrous membrane as the HPL. The BC/PETN membrane was used as a receiver to electrospin the zein/EC/PPIX and zein/EC/Vac solutions onto both sides of the BC/PETN. After hot pressing several times by the roller under the pressure of 1 $\mathrm{MPa}$, the MC membrane was formed.

\subsection{Characterization}

\subsubsection{Scanning Electron Microscopy (SEM)}

The microstructure and morphology of the samples were examined by an SEM at an accelerating voltage of $5.0 \mathrm{kV}$. The composite membranes were cut to expose the cross section, which was stuck on the microscope with a conductive adhesive. Before SEM imaging, a layer of gold was applied to the surface of the dried samples to avoid any sample charging effects. The images were collected at 200x, $1000 \times$, or $5000 \times$ magnification.

\subsubsection{Fourier Transform Infrared Spectroscopy (FTIR)}

A Thermo Fisher Scientific FTIR Nicolet iS10 spectrometer was used to record the FTIR spectrum of the samples in the range of $650-4000 \mathrm{~cm}^{-1}$, and 16 scans were performed at a resolution of $4 \mathrm{~cm}^{-1}$.

\subsubsection{Antibacterial Activity Assessment of the ABL}

Staphylococcus aureus ATCC-6538 and Pseudomonas aeruginosa CMCC(B) 10104, obtained from our laboratory, were cultured with Luria-Bertani medium (LB) on a rotary shaker at $37^{\circ} \mathrm{C}$ and 200 $\mathrm{rpm}$. When growth of bacteria was monitored by measuring the optical density (OD; 0.6-0.7, 600 $\mathrm{nm}$ ), we inoculated $0.1 \mathrm{~mL}$ of bacterial solution evenly on the surface of the culture medium plates. Samples were prepared by cutting the materials into round-shaped disks with diameters of $10 \mathrm{~mm}$. The zein/EC/PPIX membrane was tested as the treated sample, while zein/EC was set as the control, both of which were placed in bacteria-containing agar plates. After illumination for $30 \mathrm{~min}$, plates were incubated under $37^{\circ} \mathrm{C}$ for $24 \mathrm{~h}$ in a thermostatic incubator. The formed inhibition zone was recorded and the diameter was measured to calculate the average width.

\subsubsection{Mechanical Properties of the RFL}

An electronic universal testing machine (KDIII-5) was applied to test the tensile mechanical properties of the $\mathrm{BC}$ membranes (dry and wet, respectively) and the BC/PETN composite membranes. The pretension was set as $50 \mathrm{cN}$, the distance between two clamps that hold the sample was $30 \mathrm{~mm}$, the effective stretching length was $50 \mathrm{~mm}$, and the testing speed was $10 \mathrm{~mm} / \mathrm{min}$ under the temperature of $25^{\circ} \mathrm{C}$ and relative humidity of $65 \%$. Every sample was tested 5 times, and then the breaking strength, elongation at break, and Young's modulus were calculated.

\subsubsection{Hygroscopicity Test of the RFL}

The hygroscopicity test was carried out according to the Chinese standard YY/T 0471.1-2004 at room temperature $\left(21 \pm 2{ }^{\circ} \mathrm{C}\right)$ and a relative humidity of $60 \% \pm 15 \%$. To determine the swelling behavior of the BC and BC/PETN membranes, samples were prepared to a size of $2 \mathrm{~cm} \times 2 \mathrm{~cm}$, weighed (the weight was set as $\mathrm{M}_{0}$ ), and immersed into simulated body fluids at $37^{\circ} \mathrm{C}$ [20]. The swelling rate 
change of all samples and the different swelling environments were measured at a specific time point until the equilibrium as reached by using the following Formula (1):

$$
\mathrm{Q}=\left(\mathrm{M}_{1}-\mathrm{M}_{0}\right) / \mathrm{M}_{0} \times 100 \%
$$

where $\mathrm{Q}$ is the swelling ratio, while $\mathrm{M}_{1}$ represents the membrane weights at a specific time. The tests were performed in triplicate.

\subsubsection{In Vitro Biocompatibility Assay of the HPL}

The zein/EC/Vac nanofibrous membrane was plated at the bottom of the 24-well plates after sterilization. L929 cells were cultured in Dulbecco's modified Eagle's medium (DMEM; Gbico) with $10 \%$ fetal bovine serum (FBS; Gbico), and $100 \mathrm{U} / \mathrm{L}$ penicillin and $100 \mu \mathrm{g} / \mathrm{mL}$ streptomycin (Gibco, Carlsbad, CA, USA). The cells were incubated at $37^{\circ} \mathrm{C}$ under an environment with $5 \% \mathrm{CO}_{2}$. When grown to the logarithmic growth phase, L929 cells were incubated in the 24-well plates with the sterilized zein/EC/Vac nanofibrous membrane by DMEM medium containing $10 \%$ FBS. After $24 \mathrm{~h}$ of incubation, following with removal of the culture medium with 3-5 times washing in PBS (phosphate buffer saline), PBS with $2.5 \%(w / w)$ glutaraldehyde was added at $4{ }^{\circ} \mathrm{C}$ for $4 \mathrm{~h}$. Finally, the solution was removed and the membranes were washed with PBS 3 times, then dried at room temperature. The morphology of the L929 cells growing on the surface of the zein/EC/Vac nanofibrous membrane was observed by SEM.

\subsection{In Vivo Animal Experiments}

\subsubsection{Establishment of a Skin Wound Model}

Thirty-six male ICR mice ( 8 weeks old, 25-30 g) were randomly divided into three groups-sterile gauze group (Control), multilayer composite membrane group (MC), and Nano-Ag dressing group (Nano-Ag), respectively. Mice were fixed, shaved, and sterilized after anesthesia by intraperitoneal injection of $50 \mathrm{mg} / \mathrm{kg}$ pentobarbital sodium solution. Sequentially, a round full-thickness skin defect with a diameter of $10 \mathrm{~mm}$ was performed on the back of the mice. A digital camera was used to record the shape of the wound, and the diameter of the wound was scaled and compared. Finally, each wound was bandaged with wound dressings from different groups and the mice were fed in different cages. The process of the skin defect preparation is shown in Figure 2.

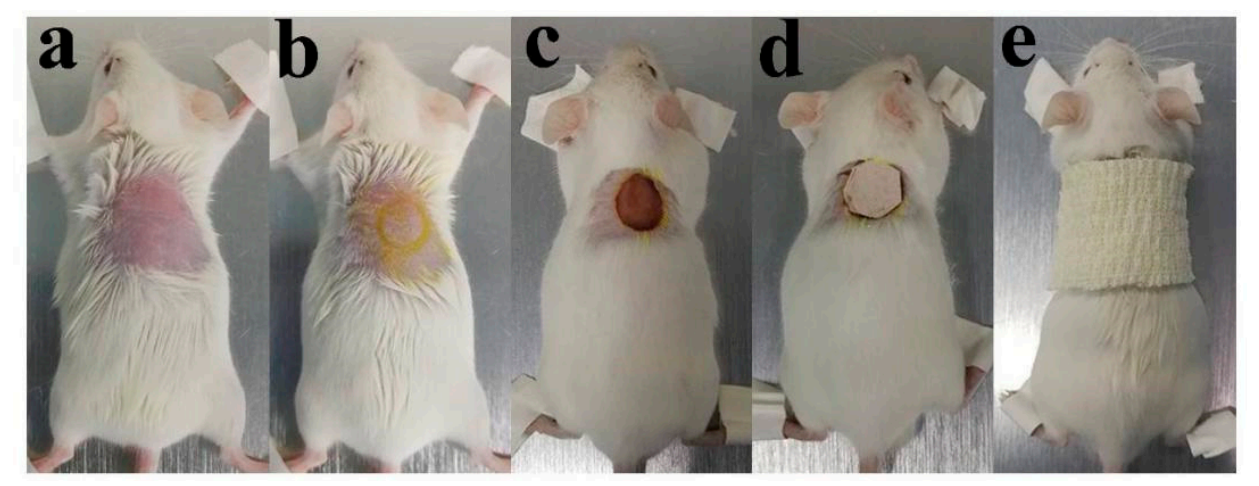

Figure 2. Process of the skin defect preparation: (a) fixed and shaved after anesthesia; (b) skin disinfection and mark on skin; (c) wound modeling; (d) dressing on wound; and (e) bandaging.

\subsubsection{Wound Observation}

Digital photographs of the wounds were recorded by a digital camera and wound size was measured on the day of operation and on various postoperative days ( $3 \mathrm{rd}, 7 \mathrm{th}$, and 10 th). The wound 
healing rate was calculated by the difference between the original wound area and the wound area on the $3 \mathrm{rd}, 7$ th, and 10th postoperative day as a percentage of the original wound area.

\subsubsection{Histological Analysis}

Skin samples were collected after 3rd, 7th, and 10th day of treatment with various dressings (4 mice were sacrificed at each time point in each group), immersed in $4 \%$ paraformaldehyde, and paraffin-embedded sections were stained with hematoxylin and eosin (H\&E; Baso, Taipei, Taiwan). All of the pathological sections were observed under a light microscope (Leica DM4000B, Leica, Wetzlar, Germany).

\subsection{Statistical Analysis}

All data are presented as mean \pm SD and analyzed using Student's $t$-test or one-way ANOVA followed by Duncan's multiple range test. $p<0.05$ was considered statistically significant.

\section{Results and Discussion}

\subsection{Morphological and FTIR Analysis}

Zein, a natural polymer material, has previously been broadly prepared by the electrospinning technique to be used as a drug carrier [21,22]. However, it is difficult to maintain the fiber morphology of zein because of its unstable and extremely swellable nature in water, limiting its application as a drug carrier [23]. Ethyl cellulose (EC) has high water stability, better general stability, fiber-forming properties during electrospinning, and good biocompatibility, which makes it a great potential for application in wound dressings [24]. Therefore, we used these two materials to electrospin, loading them with the drugs Vac and PPIX as the ABL and the HPL, respectively, and then the morphology of the different membranes was evaluated.

The nanostructure and three-dimensional network structure of the ABL can be clearly seen in Figure 3a. The nanofibers with an average diameter of $380 \pm 92 \mathrm{~nm}$ were smooth and continuous without droplets, beads, adhesion, or dissolution. The crystallization and distribution of the nanofibers were uniform and well formed with high spinnability. Figure $3 b$ shows the planar SEM image of the RFL. The nanofibers from BC were intertwined with the fibers of the PETN nonwoven fabric, and part of the BC nanofibers could intersperse between the PETN fibers, forming a three-dimensional network structure. We concluded that the $\mathrm{BC}$ fibers produced by the microorganisms firstly attached to the randomly arranged PETN fibers, and then synthesized a large number of BC nanofibers, which filled the pores and surface of the PETN to form a topological network structure [25]. The BC nanofibers were self-assembled and compounded with the nonwovens in the form of a cellulose membrane and a nanofibrous network, in which the BC membrane adhered to the surfaces of the nonwovens and the $\mathrm{BC}$ nanofibers interspersed into the voids between the PETN fibers to form a tightly bonded BC/PETN composite membrane $[25,26]$. An SEM image of HPL is shown in Figure 3c, which demonstrates that the surface of the composite nanofibers was smooth without droplets, beads, adhesion, or dissolution. Zein/EC/Vac fibers with an average diameter of $414 \pm 102 \mathrm{~nm}$ were irregular, which might be due to the increased surface tension of the mixed solution by Vac, making the jet difficult to differentiate in the electric field. Due to the surface tension of the mixed solution, the composite droplet outside the spinning nozzle was unstable when being drafted, leading to the fiber diameter being uneven and to an increasing fiber discrete degree. In addition, the drug was dissolved in the solvent and existed in the form of ions, which caused charge accumulation on the surface of the jet and divided the jet into smaller jets under relatively high electric field intensity [27]. All of the above situations would result in uneven fibers. The SEM image of the cross-section of the multilayer composite membranes shows a three-layer nanofibrous structure with an average thickness of $143 \pm 10.35 \mu \mathrm{m}$ (Figure 3d). 

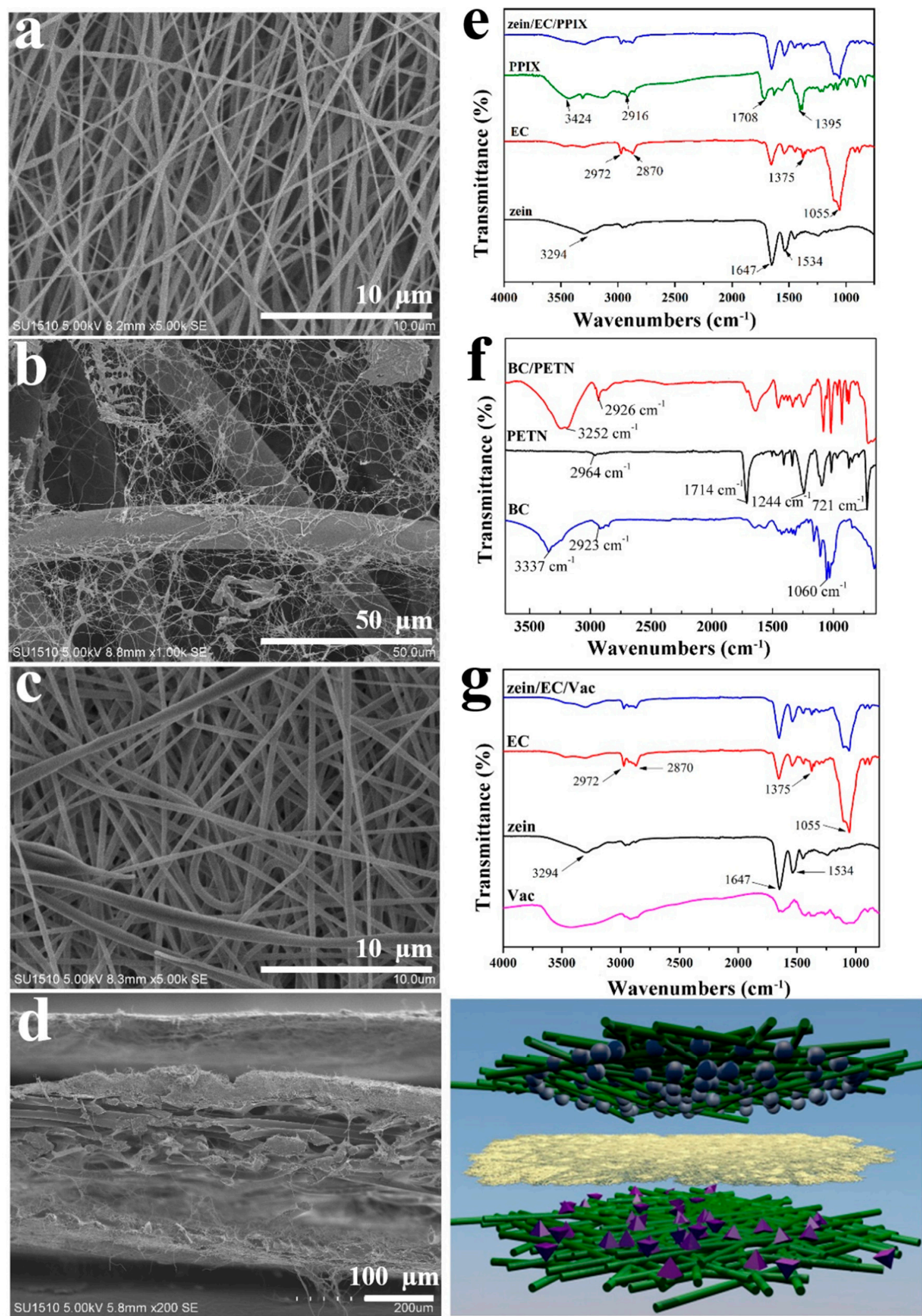

Figure 3. Scanning electronic microscope (SEM) images of the ABL (a), the RFL (b), the HPL (c), and the cross-section of the MC (d); FTIR spectra of the ABL (e), the RFL (f), the HPL (g), as well as raw materials. 
Figure 3e displays the FTIR spectrum of the ABL nanofibers. The broad peak at $3294 \mathrm{~cm}^{-1}$ in the spectra of zein was due to the stretching vibration of $\mathrm{N}=\mathrm{H}$ and $\mathrm{O}=\mathrm{H}$ of the protein chain, and the characteristic bands observed at $1647 \mathrm{~cm}^{-1}, 1534 \mathrm{~cm}^{-1}$, and $1230 \mathrm{~cm}^{-1}$ corresponded to $\mathrm{C}=\mathrm{O}$ stretching (amide I) and $\mathrm{N}=\mathrm{H}$ bending vibration (amide II) [28]. The spectra of EC illustrate that the peaks at $2972-2870 \mathrm{~cm}^{-1}, 1375 \mathrm{~cm}^{-1}$, and $1055 \mathrm{~cm}^{-1}$ represent the stretching vibration of $-\mathrm{CH}_{3}$, the bending vibration of $-\mathrm{CH}_{3}$, and $-\mathrm{C}-\mathrm{O}-\mathrm{C}$ stretching in the cyclic ether $[29,30]$. From the FTIR spectra of PPIX, three obvious characteristic peaks of stretching vibration at $3424 \mathrm{~cm}^{-1}(\mathrm{~N}-\mathrm{H}), 2916 \mathrm{~cm}^{-1}(\mathrm{C}-\mathrm{H})$, and $1708 \mathrm{~cm}^{-1}(\mathrm{C}=\mathrm{O})$ could be observed. The absorption band at $1200-1500 \mathrm{~cm}^{-1}$ was the skeleton vibration of the porphyrin ring, which could be attributed to the symmetric and asymmetric absorption peaks of the $\mathrm{C}-\mathrm{H}, \mathrm{C}=\mathrm{C}$, and $\mathrm{C}=\mathrm{N}$ bonds in the pyrrole ring [31]. The spectrum of the zein/EC/PPIX composite nanofibers had the characteristic absorption peaks of PPIX, zein, and EC without new absorption peaks, indicating that the components in the composite nanofibers were only physically mixed rather than chemically bonded. Figure $3 \mathrm{f}$ shows the FTIR spectra of the RFL. The characteristic absorption peaks of PETN at $2964 \mathrm{~cm}^{-1}, 1714 \mathrm{~cm}^{-1}, 1244 \mathrm{~cm}^{-1}$, and $721 \mathrm{~cm}^{-1}$ were assigned to the stretching vibration absorption peaks of $-\mathrm{CH}_{2},-\mathrm{C}=\mathrm{O}$, and $-\mathrm{C}-\mathrm{O}-\mathrm{C}$ in the polyethylene terephthalate macromolecular structure and the bending vibration of the $-\mathrm{CH}$ bond on the benzene ring, respectively [25]. Due to the large number of hydroxyl groups on the surface of the BC membrane, it presented a strong characteristic absorption band at $3337 \mathrm{~cm}^{-1}$ [32]. From Figure $3 \mathrm{f}$, a red-shifted hydroxyl absorption peak was observed at $3252 \mathrm{~cm}^{-1}$ after forming a composite with PETN, while the -CH stretching vibration peak around $2926 \mathrm{~cm}^{-1}$ was enhanced by the $-\mathrm{CH}$ bond in BC and PETN, implying that a good physical composite was formed between BC and PETN. From Figure 3g, the FTIR spectra of the Vac show three characteristic peaks at $3450 \mathrm{~cm}^{-1}, 1654 \mathrm{~cm}^{-1}$, and $1450 \mathrm{~cm}^{-1}$, which were associated with the stretching vibrations of $\mathrm{O}-\mathrm{H}, \mathrm{C}=\mathrm{O}$, and $\mathrm{C}=\mathrm{C}$, respectively [33]. The interactions between polymer and drug molecules such as the hydrogen bond, electrostatic adsorption, and hydrophobic effect would increase compatibility while preparing the composite nanocellulose membrane [34]. Zein and Vac possessed free hydroxyl and carboxyl groups, generating a hydrogen bond interaction in the composite nanofiber [35]. It was noted that no new absorption peak appeared in the FTIR spectrum of the zein/EC/Vac nanofibrous membrane, indicating that only physical mixing existed among the components in the drug-loaded nanofibers. It was testified that the raw materials could maintain their original activity and properties without chemical reaction.

\subsection{Antibacterial Activity Assessment of the ABL}

Figure 4a shows pictures of the inhibition zones obtained by incubating S. aureus or P. aeruginosa with the ABL membrane. The zein/EC nanofiber membranes displayed no inhibition zone, suggesting that it failed to exert an inhibition effect on S. aureus or P. aeruginosa, while the ABL membrane displayed a significant inhibition zone after the excitation by illumination. Protoporphyrin IX (PPIX), as one of the common photosensitizers, was shown to exert a significant antibacterial effect on S. aureus and E. coli. We speculated that the oxygen-free radicals generated by composite membranes loaded with PPIX can cut off the major chemical bonds, such as $\mathrm{O}-\mathrm{P}, \mathrm{C}-\mathrm{H}, \mathrm{O}-\mathrm{H}$, and $\mathrm{N}-\mathrm{H}$ bonds of bacteria, then bacteria are decomposed and the ABL exerts an effect of sterilization [36]. On the other hand, the PPIX could form singlet oxygen when being excited by illumination, which would destroy the cell membrane structure of the bacteria, reducing the vitality of the cell and inhibiting cell growth [31].

Furthermore, we also found that the inhibition zone of the ABL membrane in the P. aeruginosa group was significantly bigger than that in the $S$. aureus group $(p<0.05$, Figure $4 b)$. P. aeruginosa, also named green pus bacillus and belonging to the category of Gram-negative bacteria, is one of the major causes of hospital infections and can lead to postoperative wound infection [37]. S. aureus, as the representative bacterium of Gram-positive bacteria, can cause many serious infections and is the most common pathogen in human suppurative infection [19]. Compared to Gram-negative bacteria, Gram-positive bacteria contain peptide polysaccharide with a dense reticular structure in the thick cell wall [38]. The present study indicates that the PPIX-loaded zein/EC nanofibrous membrane possessed 
better antibacterial effects against Gram-negative bacteria, which could be relevant to the relatively thick cell wall of Gram-positive bacteria. The exact mechanism still needs further study.
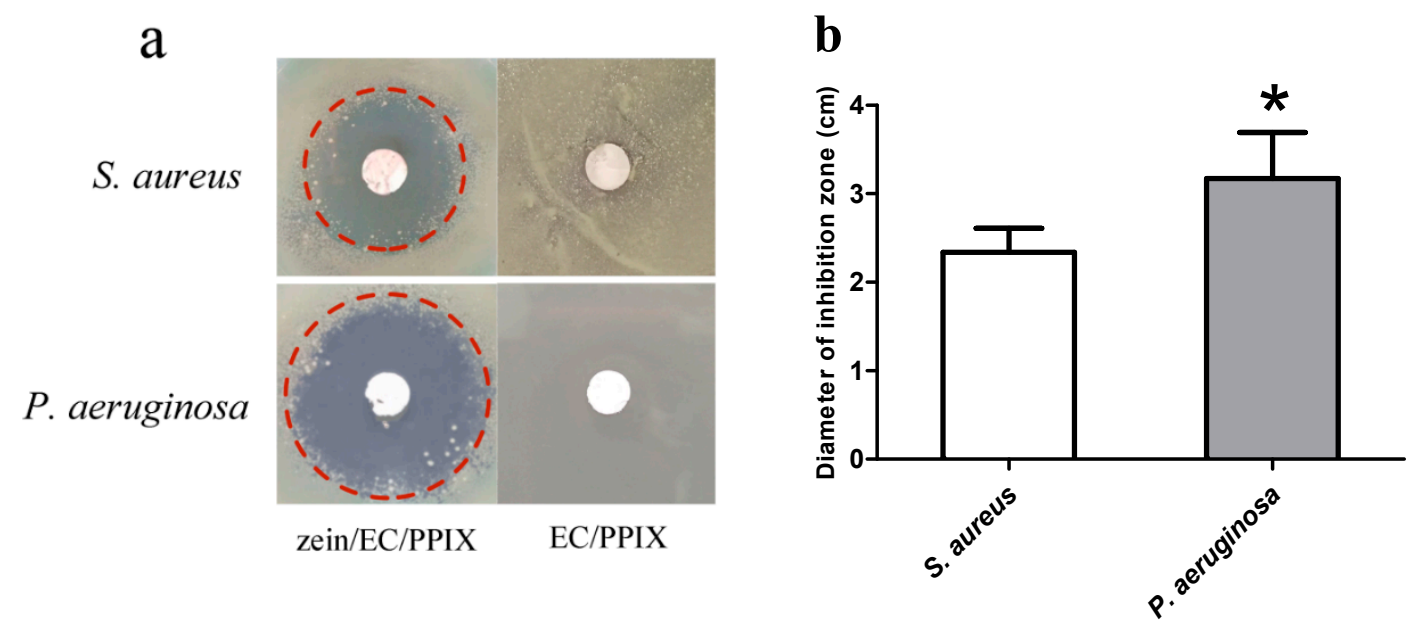

Figure 4. (a) The images of inhibition zones obtained by incubating S. aureus or P. aeruginosa with the zein/EC/PPIX nanofibrous membrane (ABL) and the EC/PPIX nanofibrous membrane. (b) Diameter statistics of the inhibition zone. * represents a statistically significant difference from the $S$. aureus group $(p<0.05)$.

\subsection{Mechanical Properties of the RFL}

$B C$ is considered a very promising wound dressing [39]. However, wet $B C$ is difficult to reprocess and dry $\mathrm{BC}$ membranes possess lower mechanical properties because of the porous matrices, showing some restricted application in wound dressings [40]. To achieve an ideal material, nonwoven composites with $\mathrm{BC}$ have shown more adequate mechanical properties in the literature [41].

As can be seen from Table 1, the BC/PETN membrane had a significantly increased elongation at the break in comparison with the dried $\mathrm{BC}$ membrane, which was similar to that of the wet $\mathrm{BC}$ membrane, suggesting that the BC/PETN membrane had good malleability. This was mainly due to the high elongation at the break of PETN itself [42]. Additionally, BC nanofibers with a network structure were filled in between the PETN fibers, and the close entanglement of the fibers greatly improved the mechanical properties of the composite membranes [43].

Table 1. The mechanical properties of the BC and BC/PETN membranes.

\begin{tabular}{cccc}
\hline Sample & $\begin{array}{c}\text { Breaking Strength } \\
\mathbf{( M P a )}\end{array}$ & Elongation at Break (\%) & Young Modulus (MPa) \\
\hline Dried BC & $7.85 \pm 2.07$ & $6.33 \pm 1.64$ & $93.6 \pm 16.4$ \\
Wet BC & $3.39 \pm 0.65^{*}$ & $34.39 \pm 5.32^{*}$ & $19.4 \pm 3.27^{*}$ \\
Dried BC/PETN & $3.40 \pm 0.34^{*}$ & $28.88 \pm 2.03^{*}$ & $11.77 \pm 1.90^{*}$ \\
\hline
\end{tabular}

* represents a statistically significant difference from the dried BC group $(p<0.05)$.

The dried BC membrane possessed a relatively higher Young modulus and larger rigidity, while the BC/PETN membrane had a decreased Young modulus in contrast to the dried BC membrane, still retaining certain strength. Considering the absorption performance, reprocessing, and easy preservation, the dried $\mathrm{BC}$ membrane was set as a layer of the multilayer composite structure for application research on wound dressings. However, the dried BC membrane was easy to break and difficult to preserve or reprocess. Non-woven fabric PETN was added for structural modification during $\mathrm{BC}$ membrane formation to modify the mechanical properties of the dried $\mathrm{BC}$ membrane 
with the mechanical effects generated from the entanglement of BC on PETN fibers and the original hydrogen bond interaction among the BC fiber.

The results revealed that the elongation at the break was largely improved, the flexibility was also increased, and malleability and strength were obtained when the $\mathrm{BC}$ membrane was combined with a non-woven fabric such as PETN to form composite materials. It successfully overcame the shortcomings of the dried BC membrane, being light, thin, crispy, and hard to spread. Meanwhile, the $\mathrm{BC} /$ PETN membrane was dry, flat, soft, resilient, and easily reprocessed, which laid the foundation for RFL application in wound dressing.

\subsection{Hygroscopicity Test of the RFL}

Modern wound-healing theories confirm that a moist healing environment can provide suitable growth conditions for cells in the damaged skin [44]. Meanwhile, an eligible wound dressing not only provides a moist and suitable microenvironment, but also reduces local pain and secondary injury caused by the removal of the dressing for wound healing [45]. However, the local wound skin becomes immersed and weakens the defense barrier against bacterial invasion when wound exudate increases. Therefore, timely drainage of wound exudate is needed to promote the healing of the wound. The ability of the wound dressing to absorb or expel wound secretions can be determined by a hygroscopicity test of the wound dressing [46].

In this experiment, the $\mathrm{BC} / \mathrm{PETN}$ and wet $\mathrm{BC}$ membranes were put into SBF solution at $37^{\circ} \mathrm{C}$, respectively, to test their hygroscopicities within $72 \mathrm{~h}$ (Figure 5). Both of the samples had a fast swelling speed within $0.5-1 \mathrm{~h}$, which then gradually decreased. The BC/PETN membrane reached equilibrium at $24 \mathrm{~h}$ with a swelling ratio of $883 \%$, indicating a good swellability. Although the wet BC membrane had hygroscopic capacity with a water swelling ratio of $82 \%$ at $48 \mathrm{~h}$, its hygroscopic ability was much lower than that of BC/PETN, which was related to the fact that the wet $\mathrm{BC}$ membrane contained a large number of water molecules. The good hygroscopicity of the BC/PETN composite membrane was attributed to the rich internal porous structure of $\mathrm{BC}$ and a three-dimensional network, resulting in a large specific surface area and a large space for adsorption of water molecules. In addition, the polyhydroxyl structure of $\mathrm{BC}$ and the upper and lower BC surface of the composite membrane also contributed to strong hydrophilicity and water swellability [47]. Therefore, the BC/PETN composite membrane, as one of the basic structures of a wound dressing, was conducive to the absorption of wound exudate and could meet the requirements as a wound dressing.

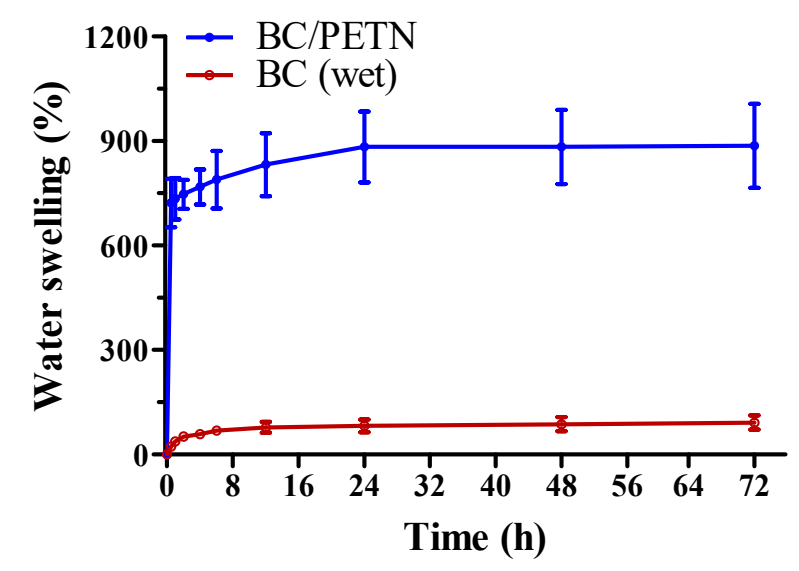

Figure 5. Water swelling ratio of the BC/PETN and BC (wet) membranes.

\subsection{In Vitro Biocompatibility Evaluation of the HPL}

Evaluation of the cell growth on the zein/EC/Vac nanofibrous membrane was observed through a cell direct contact test. As shown in Figure 6, L929 cells, growing on the surface of the nanofibrous membrane, exhibited favorable morphology in the shape of flat polygons or long spindles, and the cells 
extended well with a relatively large number of cells. This implies that the zein/EC/Vac nanofibrous membrane would be an ideal material for cell growth, with good biocompatibility.

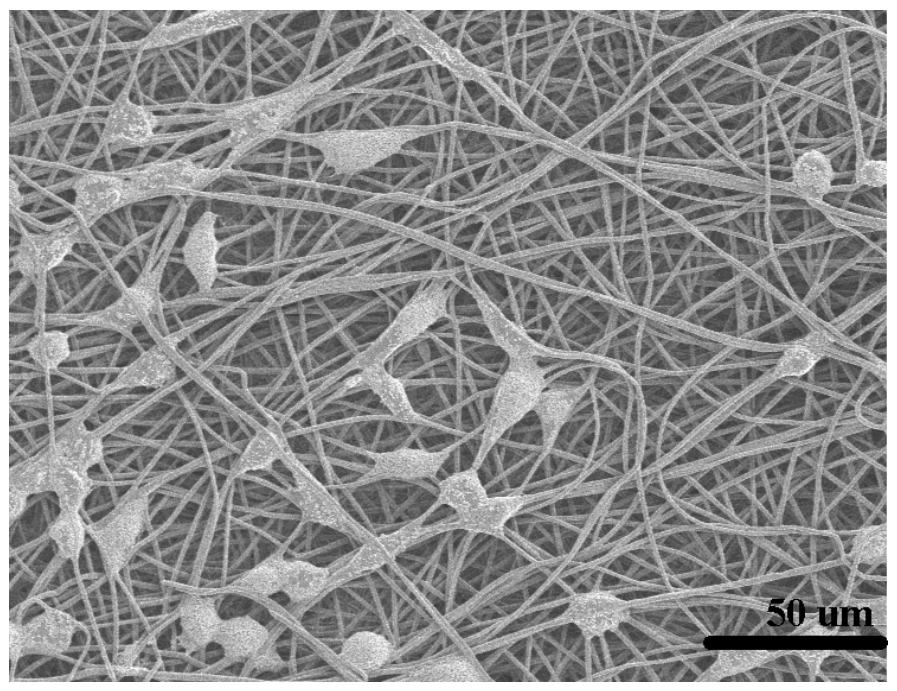

Figure 6. SEM image of L929 cells cultured on the zein/EC/Vac membrane.

Vaccarin (Vac), an extract of Vaccariae semen, showed properties of promoting specific proliferation and migration of vascular endothelial cells, contributing to neovascularization [48]. Vac loaded on the BC membranes as a wound dressing exhibited a beneficial effect due to Vac being released to promote endothelial tissue proliferation [33]. Due to the good proangiogenic effect of Vac [49], the zein/EC membrane loaded with Vac as the HPL has a good potential for application in the field of wound dressings.

\subsection{In Vivo Animal Experiment}

\subsubsection{Wound Observation}

We conducted an experiment on skin wounds using different dressings (Figure 7a). The Control group showed more severe inflammation, with redness and swelling appearing around the wound on day 3. Both the multi-layer composite wound dressing group (MC group) and the Nano-Ag wound dressing group (Nano-Ag group) promoted a small amount of new epithelial tissue proliferation, while the Nano-Ag group showed some exudate on the wound surface. On day 7, the average wound healing rates of the three groups were $28.35 \%$ (Con), $62.15 \%$ (MC), and $54.63 \%$ (Nano-Ag), respectively. As demonstrated in Figure $7 \mathrm{~b}$, the wound contraction in the MC group was remarkably higher than that in the Control and Nano-Ag groups. On day 10, the wound contraction of the MC and Nano-Ag groups reached $92.4 \%$ and $81.3 \%$ respectively, while the wound of the control group was still obvious.

We also found that the Nano-Ag dressing adhered to desiccated wound surfaces when the dressing was not removed for a long time, which induced trauma on removal. The BC layer in the MC membrane could maintain the wet healing environment of the wound due to its strong hygroscopicity. Before the dressing was removed, we firstly moistened the dressing with saline to make it reach full absorption and keep it moist, which could effectively avoid the occurrence of reinjury. 

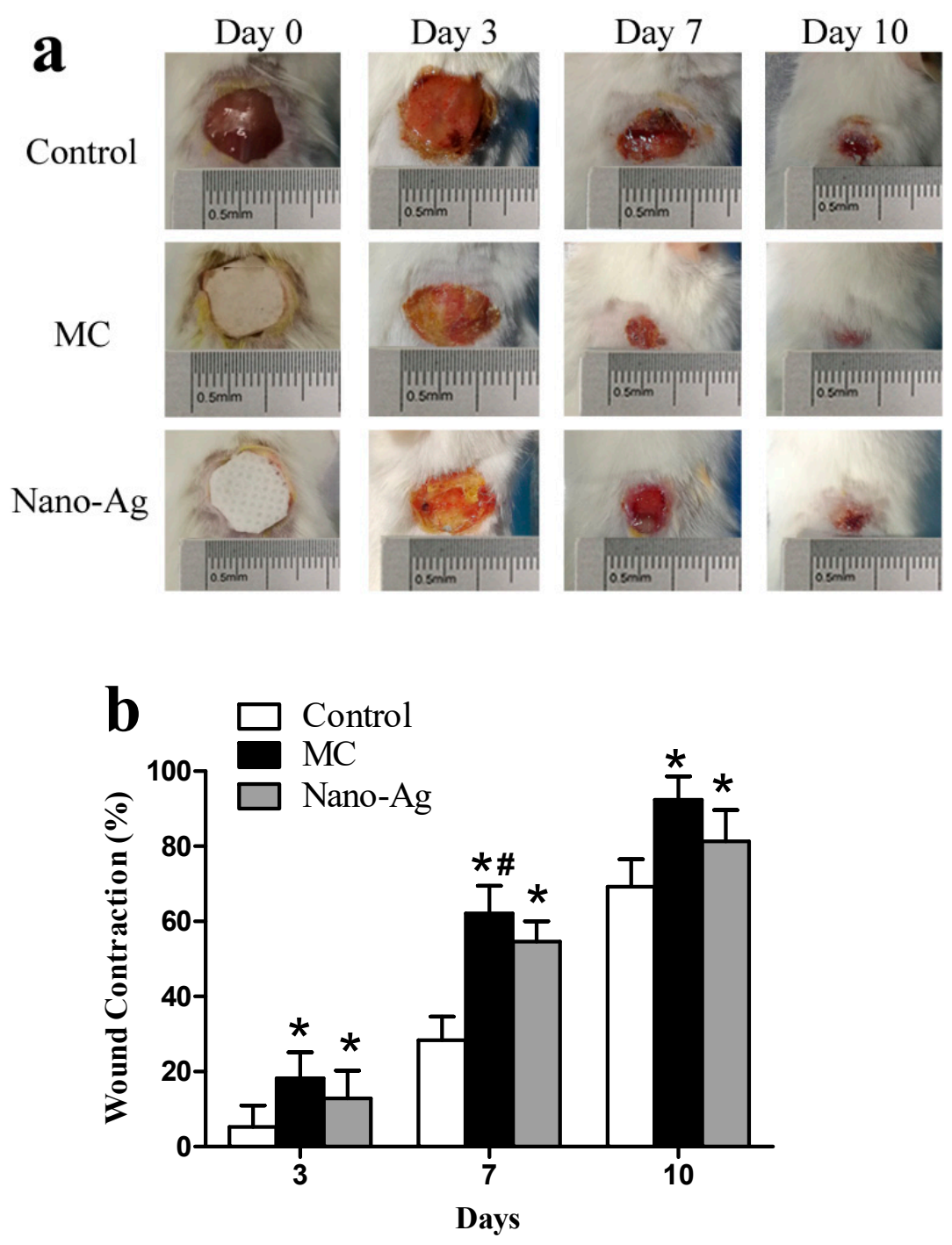

Figure 7. (a) Photographic images on days $0,3,7$, and 10 of wounds treated with sterile gauze (Control group), multilayer composite membranes (MC group), and Nano-Ag dressing (Nano-Ag group). (b) Analysis of the wound healing rate in each group on days 3, 7, and 10. * represents a statistically significant difference from the Control group $(p<0.05)$. \# represents a statistically significant difference from the Nano-Ag group $(p<0.05)$.

\subsubsection{Histological Analysis}

Wound healing is a complex biological process involving multiple cells and tissues, including tissue regeneration, epithelialization, and granulation tissue formation [50]. The pathological changes of skin wound tissues at different time points can be observed by H\&E staining. As shown in Figure 8, on day 3, a great amount of deeply colored inflammatory cells infiltrating and accumulating on the wound surface could be observed in the Control group. However, the MC group exhibited the least inflammatory cells and a small amount of neovascularization (oval, mostly on the wound surface), while some inflammatory cell infiltration and a small amount of neovascularization were observed in the Nano-Ag group. 


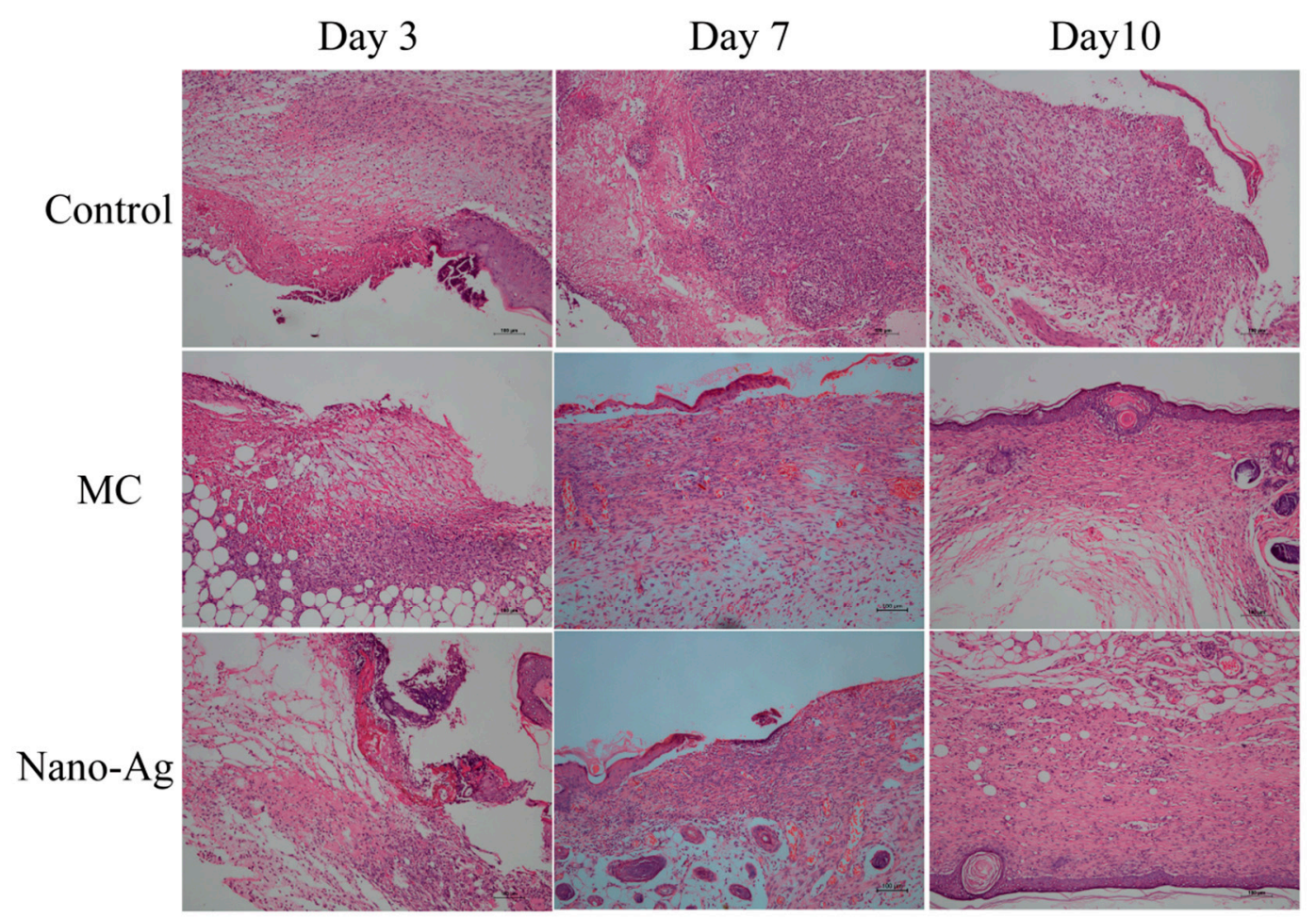

Figure 8. Histological images on days 3,7 , and 10 of the wounds treated with sterile gauze (Control group), multilayer composite membranes (MC group), and Nano-Ag dressing (Nano-Ag group).

On day 7, there were still a large number of inflammatory cells infiltrating the Control group without regular skin structure and no epidermal structure. The MC group showed less inflammatory cells and more new neovascularization and fibroblasts, and thus had basically completed epithelialization. In the Nano-Ag group, part of the epidermis and the basic epidermal structure with a few fibroblasts and abundant new neovascularization could be observed.

On day 10, the epidermal structure in the Control group was not yet completely formed. The MC and Nano-Ag groups had produced a large amount of collagen fibers on the surface of the wound, forming the structure of the epidermis. Each layer was regular and orderly on the wound surface, similar to normal skin [51]. Meanwhile, the granulation tissue had formed and grown into the wound, which was filled with granulation tissue and had begun fibrosis in the MC and Nano-Ag groups.

\section{Conclusions}

In conclusion, an MC membrane-including an ABL (zein/EC/PPIX), an HPL (zein/EC/Vac), and an RFL (BC/PETN)—used as wound dressing material was successfully prepared. Each layer was fully characterized and analyzed, the results of which confirmed that the ABL could effectively inhibit Staphylococcus aureus and Pseudomonas aeruginosa, and the RFL prepared by the in situ biological composite method possessed a desirable nanonetwork structure and exhibited good flexibility, mechanical properties, and good hygroscopicity. In addition, the HPL favored biocompatibility in vitro. The animal experiment showed that the wound healing rate of mice treated in the MC group reached $92.4 \%$ on day 10 , which was significantly higher than that of the Control group. Histological examinations demonstrated that active fibroblasts and epithelialization could be observed, and granulation tissue was filled in the wounds to complete the process of tissue remodeling treated by MC and commercial Nano-Ag dressings. Given the general properties of the MC membrane and its satisfactory performance in the mouse wound model, the MC membrane demonstrates a promising future in the design and production of next-generation wound dressing materials. 
Author Contributions: Conceptualization, Q.W. (Qufu Wei); Methodology, Q.W. (Qufu Wei) and Y.Q.; Validation, Y.Q., Y.C. and S.X.; Formal analysis, Y.Q. and Q.W. (Qingqing Wang); Data curation, Q.W. (Qufu Wei) and Y.Q.; Writing-original draft preparation, Y.Q; Writing-review and editing, Q.W. (Qufu Wei); Visualization, W.H.; Supervision, Y.C. and S.X.; Project administration, Q.W. (Qufu Wei) and Y.Q.; Funding acquisition, Q.W. (Qufu Wei) and Y.Q. All authors have read and agreed to the published version of the manuscript.

Funding: This research was funded by the Natural Science Foundation of Jiangsu Province, grant number BK20180628 and Wuxi Science and Technology Development Fund, grant number WX18IIAN011.

Conflicts of Interest: The authors declare no conflict of interest.

\section{References}

1. Rodrigues, M.; Kosaric, N.; Bonham, C.A.; Gurtner, G.C. Wound healing: A cellular perspective. Physiol. Rev. 2018, 99, 665-706. [CrossRef]

2. Wang, P.-H.; Huang, B.-S.; Horng, H.-C.; Yeh, C.-C.; Chen, Y.J. Wound healing. J. Chin. Med. Assoc. 2018, 81, 94-101. [CrossRef]

3. Dhivya, S.; Padma, V.V.; Santhini, E. Wound dressings-a review. BioMedicine 2015, 5, 24-28. [CrossRef]

4. Li, X.; Ma, M.; Ahn, D.U.; Huang, X. Preparation and characterization of novel eggshell membrane-chitosan blend films for potential wound-care dressing: From waste to medicinal products. Int. J. Biol. Macromol. 2019, 123, 477-484. [CrossRef]

5. Öztürk, E.; Ağalar, C.; Keçeci, K.; Denkbas, E.B. Preparation and characterization of ciprofloxacin-loaded alginate/chitosan sponge as a wound dressing material. J. Appl. Polym. Sci. 2006, 101, 1602-1609. [CrossRef]

6. Chen, D.W.C.; Liao, J.Y.; Liu, S.J.; Chan, E.C. Novel biodegradable sandwich-structured nanofibrous drug-eluting membranes for repair of infected wounds: An in vitro and in vivo study. Int. J. Nanomed. 2012, 7,763 .

7. $\quad$ de Oliveira Barud, H.G.; da Silva, R.R.; da Silva Barud, H.; Tercjak, A.; Gutierrez, J.; Lustri, W.R.; Ribeiro, S.J. A multipurpose natural and renewable polymer in medical applications: Bacterial cellulose. Carbohyd. Polym. 2016, 153, 406-420. [CrossRef]

8. Metcalfe, A.D.; Ferguson, M.W. Tissue engineering of replacement skin: The crossroads of biomaterials, wound healing, embryonic development, stem cells and regeneration. J. R. Soc. Interface 2006, 4, 413-437. [CrossRef] [PubMed]

9. Masaeli, E.; Karamali, F.; Loghmani, S.; Eslaminejad, M.B.; Nasr-Esfahani, M.H. Bio-engineered electrospun nanofibrous membranes using cartilage extracellular matrix particles. J. Mater. Chem. B. 2017, 5, 765-776. [CrossRef]

10. Liu, M.; Duan, X.P.; Li, Y.M.; Yang, D.P.; Long, Y.Z. Electrospun nanofibers for wound healing. Mater. Sci. Eng: C 2017, 76, 1413-1423. [CrossRef] [PubMed]

11. Naragund, V.S.; Panda, P.K. Electrospinning of Polyacrylonitrile Nanofiber Membrane for Bacteria Removal. J. Mater. Sci. Appl. 2018, 4, 68-74.

12. Pelipenko, J.; Kocbek, P.; Kristl, J. Critical attributes of nanofibers: Preparation, drug loading, and tissue regeneration. Int. J. Pharm. 2015, 484, 57-74. [CrossRef] [PubMed]

13. Hu, X.; Liu, S.; Zhou, G.; Huang, Y.; Xie, Z.; Jing, X. Electrospinning of polymeric nanofibers for drug delivery applications. J. Control Release 2014, 185, 12-21. [CrossRef] [PubMed]

14. Unnithan, A.R.; Gnanasekaran, G.; Sathishkumar, Y.; Lee, Y.S.; Kim, C.S. Electrospun antibacterial polyurethane-cellulose acetate-zein composite mats for wound dressing. Carbohyd. Polym. 2014, 102, 884-892. [CrossRef]

15. Vogt, P.M.; Andree, C.; Breuing, K.; Liu, P.Y.; Slama, J.; Helo, G.; Eriksson, E. Dry, moist, and wet skin wound repair. Ann. Plas. Surg. 1995, 34, 493-499. [CrossRef]

16. Mayet, N.; Choonara, Y.E.; Kumar, P.; Tomar, L.K.; Tyagi, C.; Du Toit, L.C.; Pillay, V. A comprehensive review of advanced biopolymeric wound healing systems. J. Pharm. Sci. 2014, 103, 2211-2230. [CrossRef]

17. Czaja, W.; Romanovicz, D.; Malcolm Brown, R. Structural investigations of microbial cellulose produced in stationary and agitated culture. Cellulose 2004, 11, 403-411. [CrossRef]

18. Chen, X.J.; Jiang, J.P.; Chen, W.H. Effect of PpIX-PDT irradiated by laser and LED. China I Laser Med. Surg. 2015, 4, 184-187. 
19. Dong, J.; Ghiladi, R.A.; Wang, Q.; Cai, Y.; Wei, Q. Protoporphyrin IX conjugated bacterial cellulose via diamide spacer arms with specific antibacterial photodynamic inactivation against Escherichia coli. Cellulose 2018, 25, 1673-1686. [CrossRef]

20. Shankhwar, N.; Kumar, M.; Mandal, B.B.; Robi, P.S.; Srinivasan, A. Electrospun polyvinyl alcohol-polyvinyl pyrrolidone nanofibrous membranes for interactive wound dressing application. J. Biomater. Sci. Polym. Ed. 2016, 27, 247-262. [CrossRef]

21. Dashdorj, U.; Reyes, M.K.; Unnithan, A.R.; Tiwari, A.P.; Tumurbaatar, B.; Park, C.H.; Kim, C.S. Fabrication and characterization of electrospun zein/Ag nanocomposite mats for wound dressing applications. Int. J. Biol. Macromol. 2015, 80, 1-7. [CrossRef] [PubMed]

22. Labib, G. Overview on zein protein: A promising pharmaceutical excipient in drug delivery systems and tissue engineering. Expert Opin. Drug Deli. 2018, 15, 65-75. [CrossRef] [PubMed]

23. Lu, H.; Wang, Q.; Li, G.; Qiu, Y.; Wei, Q. Electrospun water-stable zein/ethyl cellulose composite nanofiber and its drug release properties. Mater. Sci. Eng. 2017, 74, 86-93. [CrossRef] [PubMed]

24. Iqbal, H.M.; Kyazze, G.; Locke, I.C.; Tron, T.; Keshavarz, T. Poly (3-hydroxybutyrate)-ethyl cellulose based bio-composites with novel characteristics for infection free wound healing application. Int. J. Biol. Macromol. 2015, 81, 552-559. [CrossRef] [PubMed]

25. Huang, J.Y.; lv, P.F.; Yao, Y.X.; Wei, Q.F. Preparation and properties of self-woven composites of bacterial cellulose /polyester. Text. Res. J. 2018, 2, 126-131.

26. Grande, C.J.; Torres, F.G.; Gomez, C.M.; Troncoso, O.P.; Canet-Ferrer, J.; Martínez-Pastor, J. Development of self-assembled bacterial cellulose-starch nanocomposites. Mater. Sci. Eng. C 2009, 29, 1098-1104. [CrossRef]

27. Zeng, J.; Yang, L.X.; Liang, Q.Z.; Zhang, X.F.; Guan, H.L.; Xu, X.L.; Chen, X.S.; Jing, X.B. Influence of the drug compatibility with polymer solution on the release kinetics of electrospun fiber formulation. J. Control Release 2005, 105, 43-51. [CrossRef]

28. Yao, C.; Li, X.; Song, T.; Li, Y.; Pu, Y. Biodegradable nanofibrous membrane of zein/silk fibroin by electrospinning. Polym. Int. 2009, 58, 396-402. [CrossRef]

29. Desai, J.; Alexander, K.; Riga, A. Characterization of polymeric dispersions of dimenhydrinate in ethyl cellulose for controlled release. Int. J. Pharm. 2006, 308, 115-123.

30. Qiu, B.; Xu, C.; Sun, D.; Yi, H.; Guo, J.; Zhang, X.; Luo, Z. Polyaniline coated ethyl cellulose with improved hexavalent chromium removal. ACS Sustain. Chem. Eng. 2014, 2, 2070-2080. [CrossRef]

31. Dong, J.; Ghiladi, R.A.; Wang, Q.; Cai, Y.; Wei, Q. Protoporphyrin-IX conjugated cellulose nanofibers that exhibit high antibacterial photodynamic inactivation efficacy. Nanotechnology 2018, 29, 265601. [CrossRef] [PubMed]

32. Lv, P.; Yao, Y.; Li, D.; Zhou, H.; Naeem, M.A.; Feng, Q.; Wei, Q. Self-assembly of nitrogen-doped carbon dots anchored on bacterial cellulose and their application in iron ion detection. Carbohyd. Polym. 2017, 172, 93-101. [CrossRef] [PubMed]

33. Qiu, Y.; Qiu, L.; Cui, J.; Wei, Q. Bacterial cellulose and bacterial cellulose-vaccarin membranes for wound healing. Mater. Sci. Eng. C 2016, 59, 303-309. [CrossRef] [PubMed]

34. Choi, J.Y.; Yoo, J.Y.; Kwak, H.S.; Nam, B.U.; Lee, J. Role of polymeric stabilizers for drug nanocrystal dispersions. Curr. Appl. Phys. 2005, 5, 472-474. [CrossRef]

35. Liang, J.; Xia, Q.; Wang, S.; Li, J.; Huang, Q.; Ludescher, R.D. Influence of glycerol on the molecular mobility, oxygen permeability and microstructure of amorphous zein films. Food Hydrocoll. 2015, 44, 94-100. [CrossRef]

36. Lister, P.D.; Wolter, D.J.; Hanson, N.D. Antibacterial-resistant Pseudomonas aeruginosa: Clinical impact and complex regulation of chromosomally encoded resistance mechanisms. Clin. Microbiol. Rev. 2009, 22, 582-610. [CrossRef]

37. Bereket, W.; Hemalatha, K.; Getenet, B.; Wondwossen, T.; Solomon, A.; Zeynudin, A.; Kannan, S. Update on bacterial nosocomial infections. Eur. Rev. Med. Pharmacol. Sci. 2012, 16, 1039-1044.

38. Takeuchi, O.; Hoshino, K.; Kawai, T.; Sanjo, H.; Takada, H.; Ogawa, T.; Akira, S. Differential roles of TLR2 and TLR4 in recognition of gram-negative and gram-positive bacterial cell wall components. Immunity 1999, 11, 443-451. [CrossRef]

39. Czaja, W.; Krystynowicz, A.; Bielecki, S.; Brown, R.M., Jr. Microbial cellulose- the natural power to heal wounds. Biomaterials 2006, 27, 145-151. [CrossRef] 
40. Żywicka, A.; Peitler, D.; Rakoczy, R.; Junka, A.F.; Fijałkowski, K. Wet and Dry Forms of Bacterial Cellulose Synthetized by Different Strains of Gluconacetobacter xylinus as Carriers for Yeast Immobilization. Appl. Biochem. Biotech. 2016, 180, 805-816. [CrossRef]

41. Karabay, O.; Koçoglu, E.; Tahtaci, M. The role of mobile phones in the spread of bacteria associated with nosocomial infections. J. Infect Dev. Ctries 2007, 1, 72-73.

42. Karayannidis, G.P.; Papachristos, N.; Bikiaris, D.N.; Papageorgiou, G.Z. Synthesis, crystallization and tensile properties of poly(ethylene terephthalate-co-2,6-naphthalate)s with low naphthalate units content. Polymer 2003, 44, 7801-7808. [CrossRef]

43. Turoti, M.; Olayemi, J.Y.; Adeniyi, J.B.; Peters, O. The photooxidative degradation of poly(vinylchloride)-2. The stabilising action of dibutyltin maleate and trisnitro (1,3-dihydroxyl-2-hydroxymethyl-2-nitropropane) on PVC from ultraviolet light radiation. Polym. Degrad. Stabil. 1998, 61, 297-302. [CrossRef]

44. Field, C.K.; Kerstein, M.D. Overview of wound healing in a moist environment. Am. J. Surg. 1994, 167, 2-6. [CrossRef]

45. Abdelrahman, T.; Newton, H. Wound dressings: Principles and practice. Surgery 2011, 29, 491-495. [CrossRef]

46. Min, S.; Gao, X.; Han, C.; Chen, Y.; Yang, M.; Zhu, L.; Yao, J. Preparation of a silk fibroin spongy wound dressing and its therapeutic efficiency in skin defects. J. Biomat. Sci-Polym E. 2012, 23, 97-110. [CrossRef]

47. Wang, J.; Zhao, L.; Zhang, A.; Huang, Y.; Tavakoli, J.; Tang, Y. Novel Bacterial Cellulose/Gelatin Hydrogels as 3D Scaffolds for Tumor Cell Culture. Polymers 2018, 10, 581. [CrossRef]

48. Xie, F.; Cai, W.; Liu, Y.; Li, Y.; Du, B.; Feng, L.; Qiu, L. Vaccarin attenuates the human EA. hy926 endothelial cell oxidative stress injury through inhibition of Notch signaling. Int. J. Mol. Med. 2015, 35, 135-142. [CrossRef]

49. Xu, F.; Liu, Y.; Zhu, X.; Li, S.; Shi, X.; Li, Z.; Sun, H. Protective Effects and Mechanisms of Vaccarin on Vascular Endothelial Dysfunction in Diabetic Angiopathy. Int. J. Mol. Sci. 2019, 20, 4587. [CrossRef]

50. Young, A.; Mcnaught, C.E. The physiology of wound healing. Surgery 2011, 29, 475-479. [CrossRef]

51. Menon, G.K. New insights into skin structure: Scratching the surface. Adv. Drug Deliver Rev. 2002, 54, 3-17. [CrossRef]

(C) 2020 by the authors. Licensee MDPI, Basel, Switzerland. This article is an open access article distributed under the terms and conditions of the Creative Commons Attribution (CC BY) license (http://creativecommons.org/licenses/by/4.0/). 